\title{
Continuous infusion of angiotensin II modulates hypertrophic differentiation and apoptosis of chondrocytes in cartilage formation in a fracture model mouse
}

\author{
Hirohisa Kawahata ${ }^{1,2}$, Daisuke Sotobayashi ${ }^{2}$, Motokuni Aoki ${ }^{2}$, Hideo Shimizu ${ }^{3}$, Hironori Nakagami ${ }^{3}$, \\ Toshio Ogihara ${ }^{2}$ and Ryuichi Morishita ${ }^{1}$
}

\begin{abstract}
Although components of the renin-angiotensin system (RAS) are reported to be expressed in cultured chondrocytes and cartilage, little is known about the precise function of Angiotensin II (Ang II) in chondrocytes. In this study, we employed a rib fracture model mouse to investigate the effect of Ang II on chondrocytes. Ang II type 1 receptor (AT1R) was expressed in chondrocytes in the growth plate of mouse tibia. Continuous infusion of Ang II to rib-fractured mice resulted in a significant increase in the volume of cartilage, suggesting Ang II-induced hypertrophic differentiation of chondrocytes. It was also confirmed by a significant increase in the mRNA expression of Sox9 and runt-related transcription factor 2 (Runx2), which are genes related to chondrocyte differentiation, and type $\mathrm{X}$ collagen, matrix metalloproteinase (MMP)-13 and Indian hedgehog (Ihh), which are hypertrophic chondrocyte-specific molecular markers. Chondrocyte hypertrophy with upregulation of these genes was attenuated by administration of olmesartan, an AT1R blocker, but not by hydralazine. Moreover, Ang II infusion significantly suppressed apoptosis of chondrocytes, accompanied by significant induction of mRNA expression of bcl-2 and bcl-xL. Olmesartan, but not hydralazine, significantly attenuated the reduction of apoptotic cells and the increase in anti-apoptotic genes induced by Ang II infusion. Overall, the present study demonstrated that Ang II promoted hypertrophic differentiation of chondrocytes and reduced apoptosis of hypertrophic chondrocytes independently of high blood pressure. The present data indicate the role of Ang II in cartilage, and might provide a new concept for treatment of cartilage diseases.
\end{abstract}

Hypertension Research (2015) 38, 382-393; doi:10.1038/hr.2015.18; published online 19 February 2015

Keywords: Angiotensin II; angiotensin receptor blocker; apoptosis; AT1R; hypertrophic chondrocyte

\section{INTRODUCTION}

The renin-angiotensin system (RAS) is a major endocrine system, which has a central role in the regulation of body fluids, electrolyte balance and thereby blood pressure (BP). ${ }^{1}$ Angiotensin II (Ang II) is a main effector molecule of RAS, and exerts biological functions through binding to Ang II receptors. As Ang II is well known to affect cell proliferation, cell differentiation, cell death, inflammation and cell invasion etc, the function of Ang II via Ang II receptors is deeply implicated in atherosclerosis based on vascular remodeling and cardiac hypertrophy, independent of BP. ${ }^{2,3}$ The important role of Ang II is not limited to the cardiovascular system. The identification of expression of Ang II receptors in various cells not only indicates that Ang II is important for the regulation of body functions in a healthy state, but also suggests that Ang II has an important role in the pathogenesis of various diseases. ${ }^{4-10}$ Moreover, although RAS is classically considered to be a systemic circulating endocrine system, the existence of components of RAS in various tissues has suggested the concept of local tissue-specific RAS. ${ }^{2}$ Especially, as Ang II receptors are reported to exist in cells comprising the locomotorium, the actions of Ang II on bone/cartilage metabolism have recently been the center of interest for further understanding of the pathogenesis of osteoporosis, fracture healing and degenerative cartilage diseases, which lead to the locomotive syndrome.

Among such conditions, we have already reported the effects of Ang II on bone remodeling and the role of RAS in the pathogenesis of osteoporosis. ${ }^{11}$ However, the effects of Ang II on chondrocytes and cartilage metabolism are still unclear, although Ang II receptors were shown to be expressed in cultured chondrocytes ${ }^{12,13}$ and chondrocytes

${ }^{1}$ Department of Clinical Gene Therapy, Graduate School of Medicine, Osaka University, Osaka, Japan; ${ }^{2}$ Graduate School of Health Sciences, Morinomiya University of Medical Sciences, Osaka, Japan and ${ }^{3}$ Division of Vascular Medicine and Epigenetics, United Graduate School of Child Development, Osaka University, Osaka, Japan Correspondence: Dr M Aoki, Graduate School of Health Sciences, Morinomiya University of Medical Sciences, 1-26-16, Nanko-kita, Suminoe-ku, Osaka 559-8611, Japan. E-mail: aoki@morinomiya-u.ac.jp

or Dr R Morishita, Department of Clinical Gene Therapy, Graduate School of Medicine, Osaka University, 2-2 Yamada-oka, Suita, Osaka 565-0871, Japan E-mail: morishit@cgt.med.osaka-u.ac.jp

Received 25 November 2014; revised 8 December 2014; accepted 15 December 2014; published online 19 February 2015 
in vivo. ${ }^{14}$ Some papers reported a beneficial effect of an angiotensin converting enzyme inhibitor (ACEI) or an Ang II receptor blocker (ARB) on fracture healing ${ }^{15,16}$ in basic experiments, suggesting involvement of RAS in chondral metabolism. However, the direct effects of Ang II itself via Ang II receptors on differentiation, proliferation and apoptosis of chondrocytes, especially in vivo, are not yet fully understood. Thus, the aim of this study was to investigate the in vivo effects of Ang II on chondrocytes via binding of Ang II receptors.

The major reason for the difficulty of investigating the in vivo effects of Ang II on chondrocytes is that chondrocytes usually exist in nonvascular areas, and systemically administered Ang II does not act on Ang II receptors on chondrocytes. Thus, we employed a rib fracture model mouse with continuous infusion of Ang II in this experiment, since vascular invasion around cartilaginous cells is observed in the process of fracture healing. ${ }^{17}$ Systemically administered Ang II directly acts on chondrocytes through neo-vasculature into fracture site, and the effect of Ang II on chondrocytes via Ang II receptors expressed on chondrocytes can be investigated in this experimental model (Figure 1). Moreover, process of differentiation of chondrocytes can be observed in cartilage formation after fracture as with a growth plate, and subsequently apoptosis of hypertrophic chondrocytes can also be observed when cartilage is replaced by bone (Figure 1). Therefore, this model makes it possible to investigate the direct in vivo effect of Ang II on differentiation and apoptosis of chondrocytes via Ang II receptors, which is the aim of this study.

Here, we evaluated the effects of Ang II on differentiation and cell death of chondrocytes through the binding of Ang II type 1 receptor (AT1R), by systemic continuous infusion of Ang II and use of an AT1R blocker. The present data provide useful information about cartilage metabolism, and might suggest a new possibility for treatment of cartilage diseases such as osteoarthritis (OA), centering on RAS.

\section{METHODS}

\section{Animals and rib fracture surgery}

All animal procedures were approved by the Ethics Committee for Animal Experiments of Morinomiya University of Medical Sciences (Permit Number: 2011A006) and performed in agreement with institutional guidelines. Also, they were carried out in compliance with the law (No. 105) and notification (No. 6) of the Japanese government, and conducted according to the National Research Council's guidelines. All surgery was performed under sodium pentobarbital anesthesia, and all efforts were made to minimize suffering.

C57BL/6NJ female mice obtained from Japan SLC (Shizuoka, Japan), weighing about $20-22 \mathrm{~g}$, were used in this study. The mice were anesthetized by intraperitoneal injection of pentobarbital sodium $\left(50 \mathrm{mg} \mathrm{kg}^{-1}\right)$, and underwent rib fracture surgery. The right eighth rib of the mice was fractured, as previously described. ${ }^{18}$ An incision was made on the lateral aspect of the trunk, and the eighth rib was located and then fractured approximately $1 \mathrm{~cm}$ from the vertebral column using a pair of fine scissors. After rib fracture, mice were treated with carprofen (Zoetis, Inc., Florham Park, NJ, USA) $\left(5 \mathrm{mg} \mathrm{kg}^{-1}\right)$ by daily subcutaneous administration for 3 days.

Subsequently, mice were randomly divided into six groups as follows:

Saline (mice infused saline),

Ang II (mice infused Ang II (1000 $\left.\mathrm{ng} \mathrm{kg}^{-1} \mathrm{~min}^{-1}\right)$ ) (Sigma-Aldrich, St Louis, MO, USA),

Ang II+Olm $0.5 \mathrm{mg}$; mice infused Ang II (1000 $\left.\mathrm{ng} \mathrm{kg}^{-1} \mathrm{~min}^{-1}\right)$ and olmesartan $\left(0.5 \mathrm{mg} \mathrm{kg}^{-1}\right.$ per day),

Ang II+Olm $1 \mathrm{mg}$; mice infused Ang II (1000 $\left.\mathrm{ng} \mathrm{kg}^{-1} \mathrm{~min}^{-1}\right)$ and olmesartan $\left(1 \mathrm{mg} \mathrm{kg}^{-1}\right.$ per day),

Ang II+Olm $3 \mathrm{mg}$; mice infused Ang II (1000 ng $\left.\mathrm{kg}^{-1} \mathrm{~min}^{-1}\right)$ and olmesartan ( $3 \mathrm{mg} \mathrm{kg}^{-1}$ per day),

Ang II+Hyd; mice infused Ang II $\left(1000 \mathrm{ng} \mathrm{kg}^{-1} \mathrm{~min}^{-1}\right)$ and hydralazine (10 $\mathrm{mg} \mathrm{kg}^{-1}$ per day).

Ang II and/or antihypertensive drugs were infused using an osmotic minipump (DURECT Corporation, Cupertino, CA, USA), as performed in our previous study. ${ }^{11}$ For osmotic pump preparation, Ang II $\left(1000 \mathrm{ng} \mathrm{kg}^{-1-}\right.$ $\min ^{-1}$ ), olmesartan and hydralazine (Novartis Pharma, Tokyo, Japan) were dissolved in saline containing $2.5 \% \mathrm{NaHCO}_{3}$ or saline. Osmotic pumps were implanted subcutaneously, and saline, Ang II and/or antihypertensive drugs
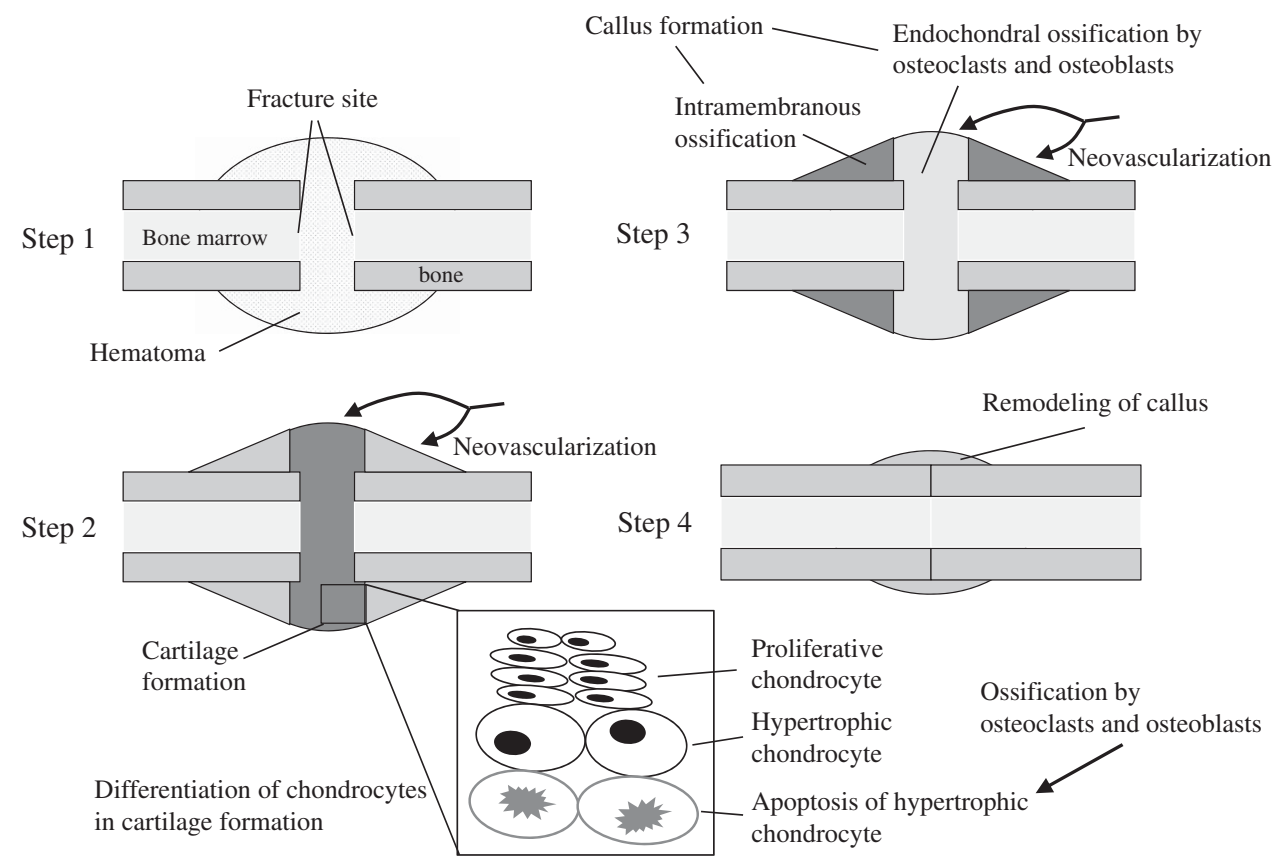

Figure 1 Process of fracture healing. Cartilage is formed after fracture, accompanied by invasion of neovasculature. Hypertrophic differentiation of chondrocytes is observed in the process of cartilage formation, and subsequently apoptosis of hypertrophic chondrocytes occurs. Osteoblasts perform endochondral ossification, and cartilage is replaced by bone followed by fracture healing. 
were infused using an Alzet model 2004 (DURECT Corporation). At 2 or 4 weeks after operation, systolic BP (SBP) was measured using the tail-cuff method (MK-1030, Muromachi Kikai, Tokyo, Japan), and body weight was measured at the same time. For histological and immunohistochemical studies of the growth plate, a tibia was isolated from an untreated female mouse under anesthesia.

\section{Histological and immunohistochemical studies}

Mice were killed at 2 or 4 weeks after rib fracture surgery by intraperitoneal administration of an overdose of pentobarbitone. The excised tissue including the fracture site was fixed with $4 \%$ paraformaldehyde in $0.1 \mathrm{M}$ phosphate buffer (pH 7.4). It was decalcified with Morse's solution, and processed for routine paraffin embedding. Tissue cross sections $(5 \mu \mathrm{m})$ were stained with hematoxylin and eosin (HE) or toluidine blue in a standard manner. To assess the volume of cartilage formation, the area occupied by chondrocytes and cartilage matrix stained with toluidine blue was quantified using an image analysis system, Image J (NIH).

For immunohistochemical staining, anti-AT1R (Abcam, Cambridge, MA, USA), anti-type X collagen antibody (LSL, Tokyo, Japan) and anti-MMP-13 antibody (eBioscience, San Diego, CA, USA) were used to analyze the expression of AT1R in chondrocytes and the secretion of col 10 and matrix metalloproteinase-13 (MMP-13) as specific markers of hypertrophic chondrocytes. Immunohistochemical staining was performed using the high polymer, HISTOFINE simple stain mouse MAX-PO (Nichirei Bioscience, Tokyo, Japan) method, as described previously. ${ }^{19}$ Briefly, $5-\mu \mathrm{m}$ sections were deparaffinized, rehydrated before blocking endogenous peroxidase activity with 3\% hydrogen peroxide, and preincubated with $1.5 \%$ blocking reagent (Roche Applied Science, Indianapolis, IN, USA) in Tris-HCl-buffered saline for $1 \mathrm{~h}$. Diluted primary antibodies (AT1R 1:100, col 10 1:1000, MMP-13 1:400) were then applied to the sections, and these sections were incubated for $1 \mathrm{~h}$. Following this, the specimens were rinsed twice with Tris-HCl-buffered saline for $5 \mathrm{~min}$ and incubated with HISTOFINE simple stain mouse MAX-PO (rat) (Nichirei Bioscience, Tokyo, Japan) for $30 \mathrm{~min}$. Peroxidase activity was visualized by treatment with $0.05 \%$ diaminobenzidine containing $0.3 \%$ hydrogen peroxide. After the samples were rinsed in water, the sections were dehydrated, cleared and mounted.

To evaluate apoptotic activity of hypertrophic chondrocytes, TUNEL staining was performed. The TUNEL method was applied to paraffin sections using an in situ apoptosis detection kit (Takara Bio, Shiga, Japan), according to the manufacturer's specifications.

\section{Real-time PCR}

Excised tissues were homogenized in cold phosphate-buffered saline and centrifuged at $20000 \mathrm{~g}$ for $15 \mathrm{~min}$ at $4{ }^{\circ} \mathrm{C}$. Total RNA of tissue samples was extracted using ISOGEN II (NIPPON GENE, Toyama, Japan), resuspended in phosphate-buffered saline, and its purity was assessed by spectrophotometry. Only samples with a ratio of spectrophotometric absorbance at $260 \mathrm{~nm}$ to that at $280 \mathrm{~nm}(\mathrm{~A} 260 / \mathrm{A} 280)$ in the range of 1.9-2.1 were used. Complementary DNA was synthesized using an iScript cDNA Synthesis Kit (Bio-Rad Laboratories, Hercules, CA, USA). Amplification reactions were performed with SsoFast EvaGreen Supermix (Bio-Rad Laboratories), with $100 \mu \mathrm{m}$ primers and $1 \mu \mathrm{g}$ cDNA in a final volume of $20 \mu \mathrm{l}$. Amplification reactions were carried out in a MiniOpticon Real-Time PCR Detection System (Bio-Rad Laboratories), according to the manufacturer's instructions $\left(1 \mathrm{~min}\right.$ at $95^{\circ} \mathrm{C}$ followed by 40 cycles of $1 \mathrm{~s}$ at $95^{\circ} \mathrm{C}$ and $5 \mathrm{~s}$ at $61-65^{\circ} \mathrm{C}$ ) with each primer. The expression level of GAPDH as the internal control was used as a housekeeping gene, and the comparative $\mathrm{Ct}$ method $\left(2^{\Delta \Delta} \mathrm{Ct}\right)$ was used to quantify gene expression levels. Values are shown as relative expression by delta $\mathrm{Ct}$ (subtraction of the crossing point cycle for the housekeeping gene from those for the genes analyzed). Sequences of primers are shown in Table $1 .{ }^{20-25}$ The oligonucleotides were synthesized by Gene Design (Suita, Japan).

\section{Statistical analysis}

All numerical values are expressed as mean \pm s.e.m. Data sets were analyzed by analysis of variance (ANOVA) followed by Scheffe F test or Tukey-Kramer post hoc test. Differences of $P<0.05$ were considered as statistically significant.
Table 1 Primers designed for real-time PCR

\begin{tabular}{|c|c|c|}
\hline Name & Sense primer $\left(5^{\prime}-3^{\prime}\right)$ & Antiense primer $\left(5^{\prime}-3^{\prime}\right)$ \\
\hline Sox9 & GAGCCGGATCTGAAGATGGA & GCTTGACGTGTGGCTTGTTC \\
\hline Runx2 & AGATGATGACACTGCCACCTCTG & GGGATGAAATGCTTGGGAACTGC \\
\hline $\begin{array}{l}\text { Type X } \\
\text { collagen }\end{array}$ & TCTGGGATGCCGCTTGT & CGTAGGCGTGCCGTTCTT \\
\hline MMP-13 & TGATGAAACCTGGACAAGCA & CCTGGGTCCTTGGAGTGAT \\
\hline Ihh & TGGACTCATTGCCTCCCAGA & CAAAGGCTCAGGAGGCTGGA \\
\hline bcl-2 & TCGCAGAGATGTCCAGTCAG & ATGCCGGTTCAGGTACTCAG \\
\hline bcl-xL & TCAGAGCTTTGAGCAGGTAGTG & TCCCGTAGAGATCCACAAAAG \\
\hline Bax & TGCAGAGGATGATTGCTGAC & GATCAGCTCGGGCACTTTAG \\
\hline GAPDH & ATGGTGAAGGTCGGTGTGA & CCATGTAGTTGAGGTCAATGAG \\
\hline
\end{tabular}

Abbreviations: Bax, BCL-2-associated X protein; bcl-2, B-cell leukemia/lymphoma-2; GAPDH, glyceraldehyde-3-phosphate dehydrogenase; Ihh, Indian hedgehog. MMP-13, matrix metalloproteinase-13; Runx2, runt-related transcription factor 2; Sox9, SRY-box containing gene 9.

\section{RESULTS}

\section{Expression of AT1R in chondrocytes}

First, the expression of AT1R in in vivo chondrocytes was evaluated. HE staining of the proximal epiphyseal growth plate of the tibia from untreated mice revealed the process of chondrocyte differentiation (Figure 2a). Immunohistochemical study of sequential sections demonstrated strong expression of AT1R in hypertrophic chondrocytes (Figure 2b), while only weak expression of AT1R could be detected in proliferating chondrocytes and pre-hypertrophic chondrocytes. Validation of the specificity of the antibody was confirmed by a negative control (Figure 2c). Also, the anti-AT1R antibody employed in this experiment was used in previous reports. ${ }^{26,27}$

\section{Cartilage formation in process of fracture healing}

As shown in Table 2, continuous infusion of Ang II by osmotic pump resulted in a significant increase in SBP, demonstrating an increase in plasma circulating Ang II level. Administration of olmesartan (0.5, 1 and $3 \mathrm{mg} \mathrm{kg}^{-1}$ per day) and hydralazine to Ang II-infused mice attenuated the increase in SBP, with no significant difference between the reduction of SBP by olmesartan and by hydralazine (Table 2). To assess the effects of Ang II on chondrocytes and endochondral ossification, we employed rib fracture model mice in which cartilage formation is observed in the process of fracture healing. At 2 weeks after rib fracture, a large volume of cartilage formation was observed in Ang II-infused rats by toluidine blue staining, as shown in Figure 3a. Cartilage area was significantly increased in Ang II-infused rats as compared with that in control (Figure 3b). Interestingly, continuous administration of olmesartan, an ARB, significantly inhibited the Ang II-induced increase in cartilage area, whereas administration of hydralazine did not (Figure 3), despite the same reduction of $\mathrm{BP}$ (Table 2). These data suggest that the large volume of cartilage formation was due to Ang II via ATR1 activation, independent of hypertension. Also, a significant increase in the volume of cartilage formation in Ang II-infused rats was still observed at 4 weeks after fracture (Figure 4), indicating a delay of endochondral ossification followed by fracture healing by infusion of Ang II.

\section{Effect of Ang II on differentiation of chondrocytes}

Cartilage in the process of fracture healing consists of cartilage matrix and chondrocytes. As shown in Figure 5a, the number of hypertrophic chondrocytes in cartilage was significantly increased in Ang II-infused mice as compared with that in control mice at 2 weeks after rib fracture. The increase in the number of hypertrophic chondrocytes 


\section{a}

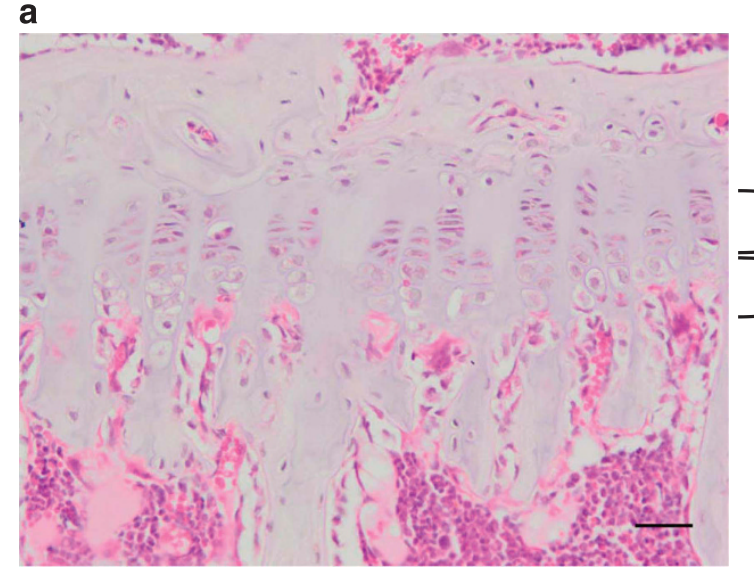

b

c

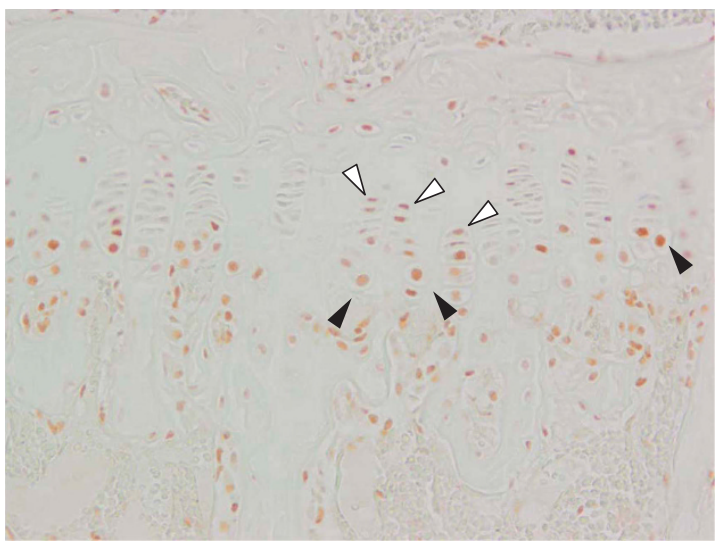

Zone of proliferating chondrocytes

Zone of hypertrophic chondrocytes

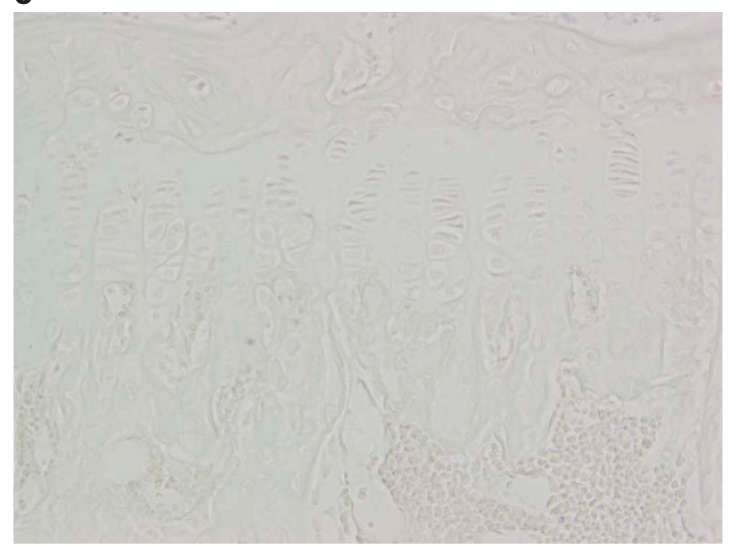

Figure 2 (a) Representative photomicrographs of HE staining. A section through the proximal growth plate of the tibia from a mouse. (b) Representative photomicrographs of growth plate of a mouse assessed by immunohistochemical staining using anti-ATR1 antibody. Opened arrowheads indicate representative stained proliferating chondrocytes and closed arrowheads indicate representative stained hypertrophic chondrocytes. (c) Negative control without antibody to AT1R (only secondary antibody was used). Magnification is $\times 200$ and scale bar is $50 \mu \mathrm{m}$.

Table 2 Effect of administration of Ang II and antihypertensive drugs on body weight and systolic blood pressure

\begin{tabular}{lrr}
\hline & Body weight $(g)$ & SBP $(\mathrm{mmHg})$ \\
\hline Saline & $19.1 \pm 1.1$ & $83.6 \pm 2.9$ \\
Ang II & $18.9 \pm 0.7$ & $153.1 \pm 8.0^{* *}$ \\
Ang II+olm 0.5 mg & $20.0 \pm 0.9$ & $93.5 \pm 4.6^{\dagger \dagger}$ \\
Ang II+olm 1 mg & $20.4 \pm 1.2$ & $88.6 \pm 3.6^{\dagger \dagger}$ \\
Ang II+olm 3 mg & $20.0 \pm 1.0$ & $77.3 \pm 3.9^{\dagger \dagger}$ \\
Ang II+hyd 10 mg & $19.3 \pm 1.3$ & $84.5 \pm 6.1^{\dagger \dagger}$ \\
\hline
\end{tabular}

Abbreviations: Ang II, Angiotensin II; SBP, systolic blood pressure.

Saline; rats infused by saline, Ang II; rats infused by Ang II (1000 $\left.\mathrm{ng} \mathrm{kg}^{-1} \mathrm{~min}^{-1}\right)$, Ang II+olm $0.5 \mathrm{mg}$; rats infused by Ang II (1000 $\left.\mathrm{ng} \mathrm{kg}^{-1} \mathrm{~min}^{-1}\right)$ and $0.5 \mathrm{mg} \mathrm{kg}^{-1}$ per day of olmesartan, Ang II+olm $1 \mathrm{mg}$; rats infused by Ang II (1000 $\mathrm{ng} \mathrm{kg}^{-1} \mathrm{~min}^{-1}$ ) and $1 \mathrm{mg} \mathrm{kg}^{-1}$ per day of olmesartan, Ang II+olm $3 \mathrm{mg}$; rats infused by Ang II (1000 $\left.\mathrm{ng} \mathrm{kg}^{-1} \mathrm{~min}^{-1}\right)$ and $3 \mathrm{mg} \mathrm{kg}^{-1}$ per day of olmesartan, Ang II+hyd; rats infused by Ang II (1000 $\left.\mathrm{ng} \mathrm{kg}^{-1} \mathrm{~min}^{-1}\right)$ and $10 \mathrm{mg} \mathrm{kg}^{-1}$ per day of hydralazine. $N=5$ per group.

${ }_{* *} P<0.01$ vs. Saline, ${ }^{\dagger+} P<0.01$ vs Ang II.

was attenuated by administration of olmesartan, whereas the same reduction of $\mathrm{BP}$ by hydralazine did not affect the number of hypertrophic chondrocytes.

The expression of mRNA of Sox 9 and Runx2, genes related to hypertrophic differentiation of chondrocytes, was significantly higher in Ang II-infused mice than in control mice at 2 weeks after rib fracture (Figures $5 \mathrm{~b}$ and $\mathrm{c}$ ). Moreover, mRNA expression of type $\mathrm{X}$ collagen, MMP-13 and Indian hedgehog (Ihh), which are hypertrophic chondrocyte-specific molecular markers, was significantly upregulated by infusion of Ang II (Figures 5d-f). Of importance, upregulation of their expression was suppressed by administration of olmesartan, but not hydralazine (Figures $5 \mathrm{~b}$ and $\mathrm{f}$ ). Immunochemical staining for col 10 and MMP-13 demonstrated that the secretion of type X collagen and MMP-13 from hypertrophic chondrocytes was promoted by Ang II infusion, while it was inhibited by administration of olmesartan, as shown in Figure 6. These data suggest that Ang II promoted differentiation of chondrocytes and accumulation of hypertrophic chondrocytes in cartilage after bone fracture, independently of elevated BP.

\section{Effect of Ang II on cell death of chondrocytes}

In the process of fracture healing, apoptosis of hypertrophic chondrocytes in cartilage occurs naturally, followed by recruitment of osteoblasts and endochondral ossification. In Ang II-infused mice, the number of TUNEL-positive hypertrophic chondrocytes was significantly decreased at 4 weeks after rib fracture (Figure 7), whereas administration of olmesartan significantly attenuated the reduction of apoptosis of hypertrophic chondrocytes (Figure 7). The decrease in apoptosis induced by Ang II infusion was not changed by administration of hydralazine (Figure 7). Moreover, the expression of bcl-2 
a
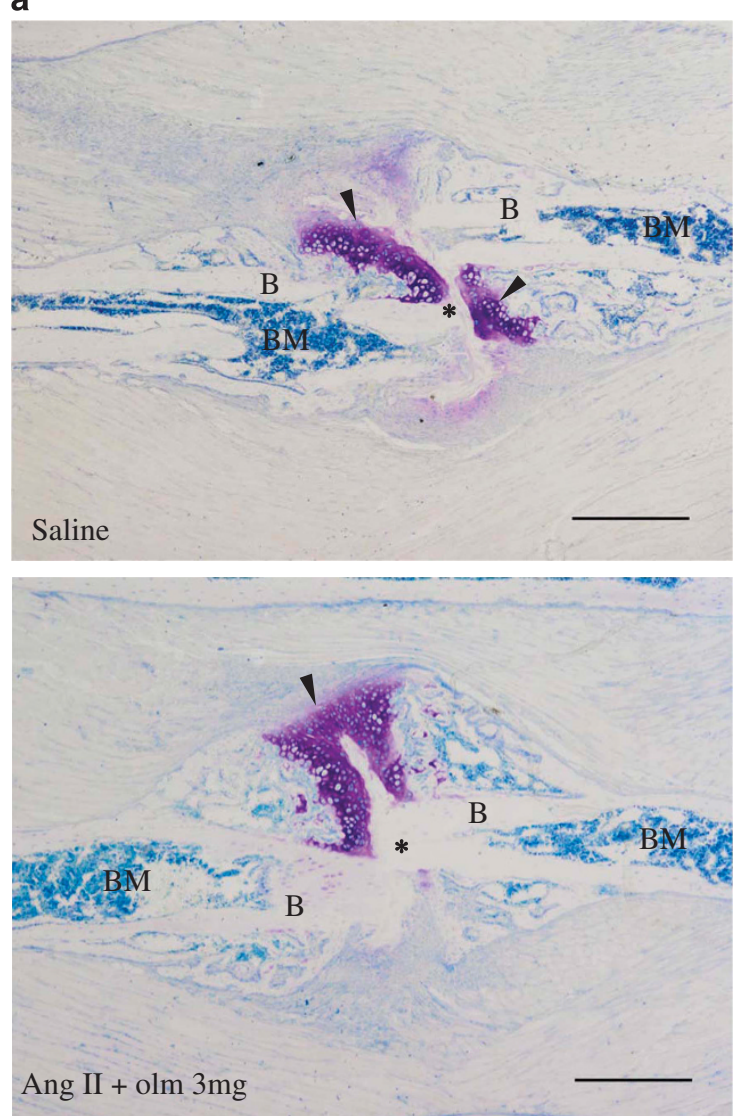

\section{b}

Area of cartilage

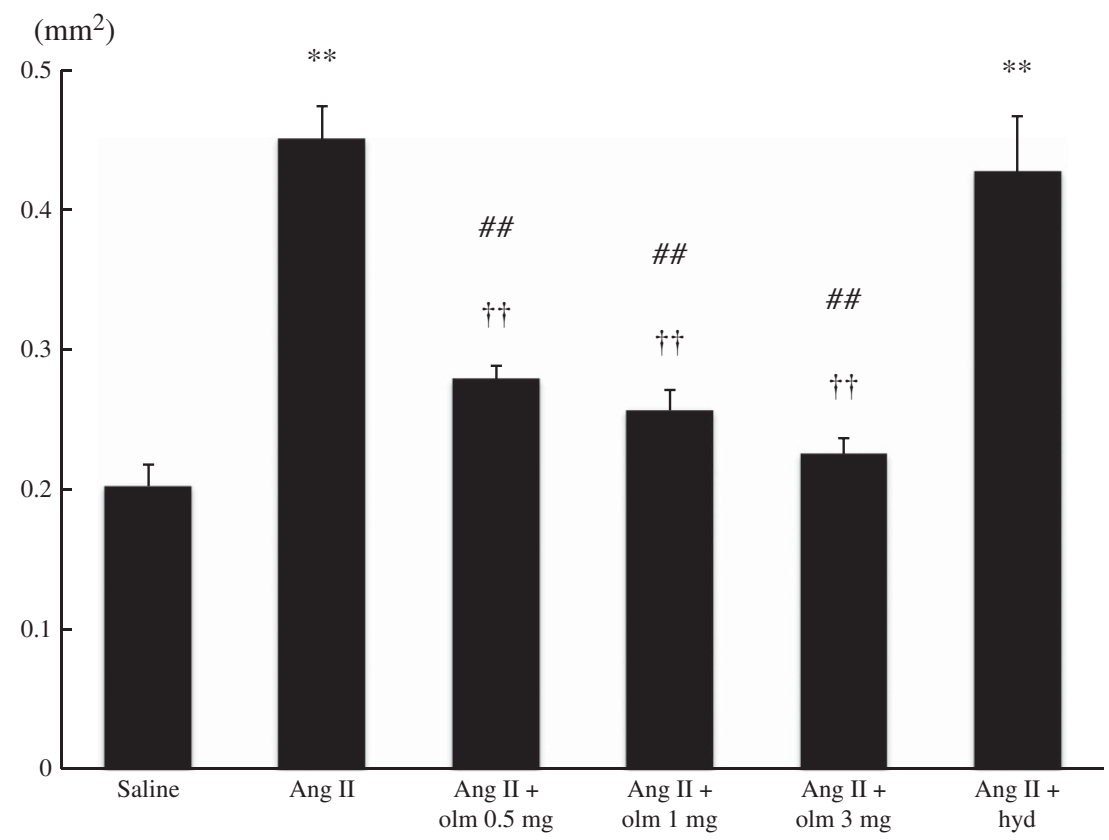

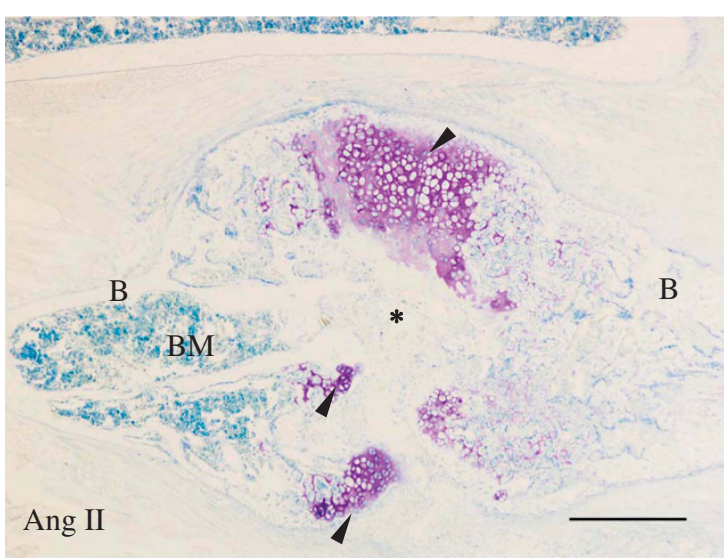

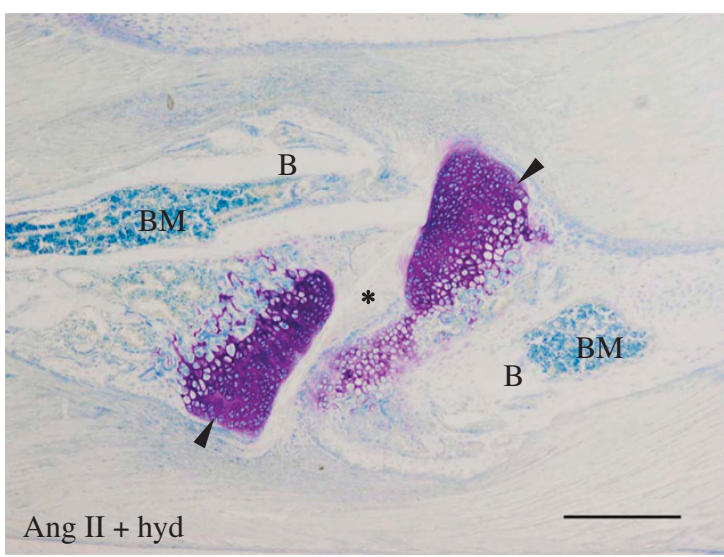

Ang II + hyd 
a
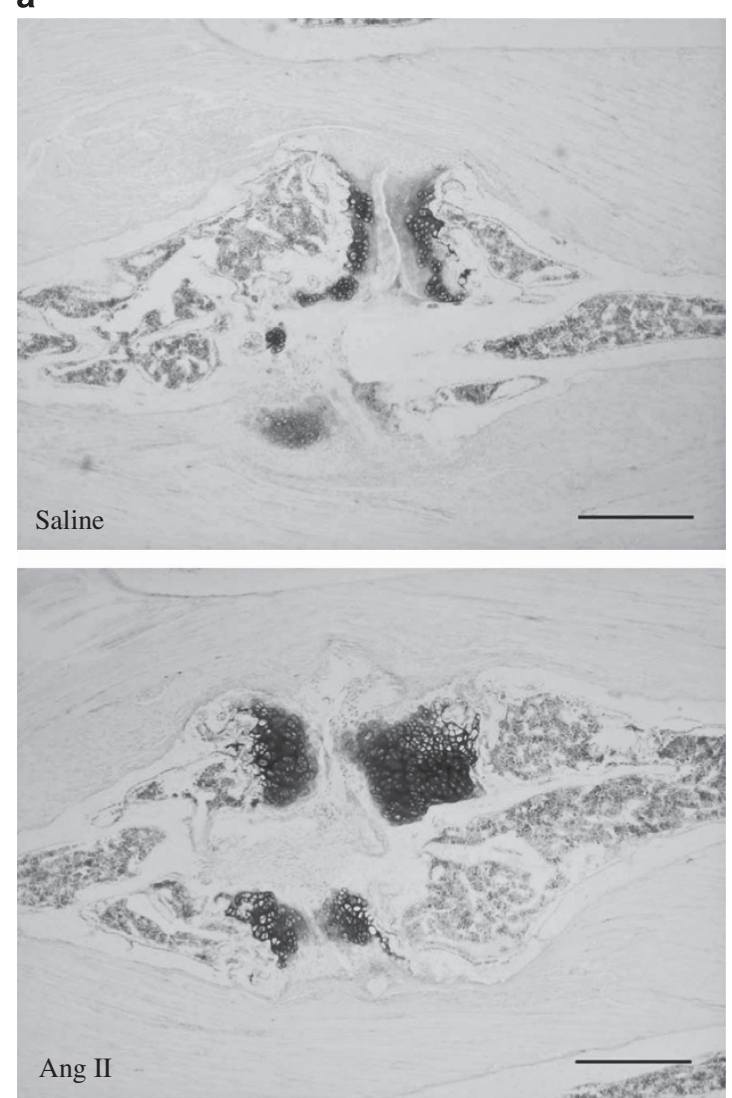

b

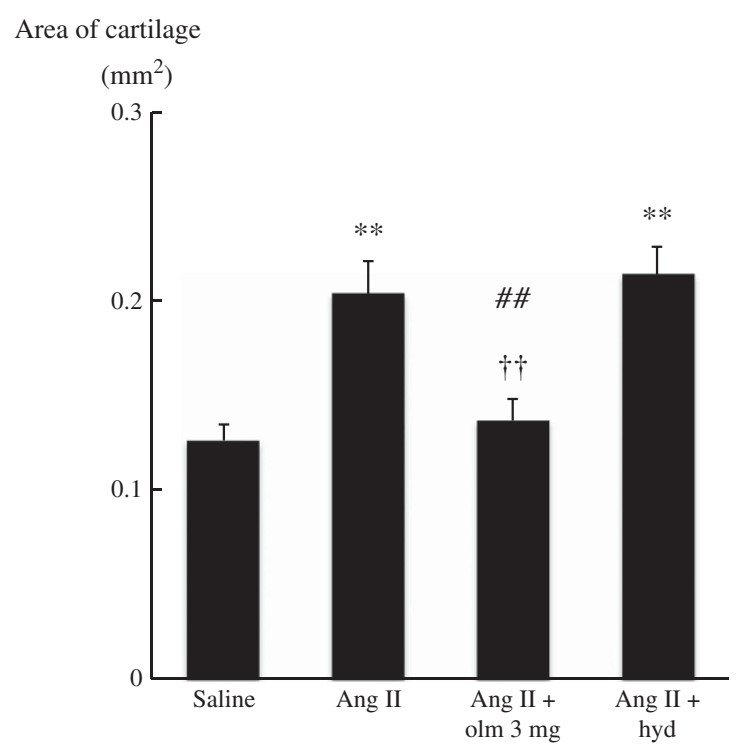

Figure 4 (a) Cartilage formation at 4 weeks after rib fracture surgery assessed by toluidine blue staining. Magnification is $\times 200$ and scale bar is $0.5 \mathrm{~mm}$. (b) Quantitative analysis of cartilage area. $N=5$ per group. Values are expressed as mean \pm s.e.m. ${ }^{* *} P<0.01$ vs. Saline, ${ }^{\dagger \dagger} P<0.01$ vs. Ang II, \#\# $P<0.01$ vs. Ang $\mathrm{II}+$ hyd. A full color version of this figure is available at the Hypertension Research journal online.

and bcl-xL, anti-apoptotic genes, was significantly induced in Ang IIinfused mice as compared with control, whereas upregulation of their expression was inhibited by administration of olmesartan (Figures $8 \mathrm{a}$ and b). In contrast, Ang II did not affect the expression of Bax, a proapoptotic gene (Figure 8c). Inhibition of apoptosis of hypertrophic chondrocytes by Ang II, combined with Ang II-promoted hypertrophic differentiation, resulted in a large volume of remaining cartilage and a delay of endochondral ossification and fracture healing (Figure 1).

\section{DISCUSSION}

The role of RAS in bone/cartilage metabolism is of recent interest. Regarding bone, the involvement of Ang II in the mechanisms of bone remodeling has been indicated in clinical settings. An inhibitory effect of ACEIs and ARBs on bone mass was reported. ${ }^{28,29}$ Also, we recently reported that an $\mathrm{ARB}$, but not a calcium channel blocker, attenuated the time-dependent increase in bone resorption markers in a clinical study employing bedridden elderly hypertensive women with disuse syndrome with severely accelerated bone resorption. ${ }^{30}$ In basic experiments, it has been already reported that osteoblasts and osteoclasts in cell cultures express receptors for Ang II. ${ }^{31,32}$ Our previous study demonstrated that Ang II increased RANKL expression in osteoblasts, and promoted differentiation and activation of osteoclasts, followed by progression of bone resorption. ${ }^{11,33}$ Also, other studies showed that Ang II promoted bone resorption, ${ }^{31,34,35}$ and Ang II suppressed osteoblastic cell differentiation and bone formation. ${ }^{36}$ Moreover, a previous experiment using an AT1a receptor-deficient mouse demonstrated similar data that ATla receptor negatively regulates bone turnover and bone mass. ${ }^{37}$ Thus, the effect of Ang II on osteoblasts and osteoclasts is becoming clear.

On the other hand, some epidemiological surveys have shown a correlation of cardiovascular disease with OA. ${ }^{38,39}$ Although it is natural that concurrence of these diseases is commonly observed in the elderly population, these reports suggest linkage of the pathophysiology between these diseases. As well as RAS in bone, one of the putative mechanisms of their linkage is RAS in cartilage. However, in contrast to bone, little is known about the effects of Ang II on chondrocytes and cartilage despite the existence of Ang II receptors in chondrocytes. ${ }^{12,13}$ Various reports suggest the importance of RAS in chondrocytes. An anti-arthritic effect of blockade of RAS by ARBs has been reported. ${ }^{40,41}$ Also, it was reported that expression of components of RAS was observed in the fracture callus, ${ }^{15,16}$ and that administration of an $\mathrm{ACEI}^{15}$ or an $\mathrm{ARB}^{16}$ increased callus formation, followed by stimulation of fracture healing in an animal fracture model. Furthermore, an interesting recent report demonstrated increased expression of components of RAS in chondrocytes that have undergone hypertrophy. ${ }^{14}$ Although this finding strongly suggests the involvement of a local RAS in chondrocyte hypertrophy, it should be elucidated whether induction of expression of RAS components is the cause or the result of hypertrophic differentiation and how Ang II itself functions to regulate differentiation, proliferation and apoptosis of chondrocytes in vivo. Moreover, there is no report demonstrating whether Ang II influences, via Ang II receptors, expression of genes related to chondrocyte differentiation, hypertrophic chondrocyte-specific 
a

hypertrophic chondrocytes

/total chondrocyte ratio

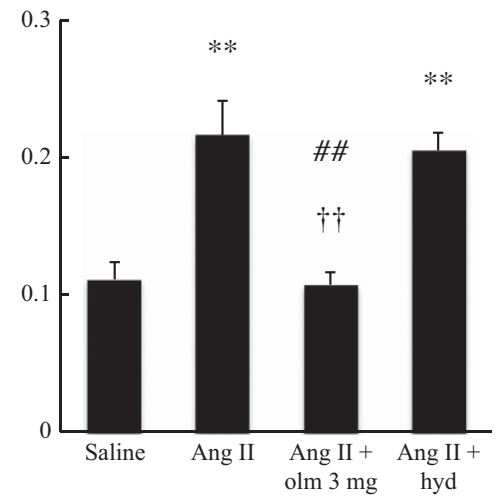

C

Relative expression

Runx2 / GAPDH

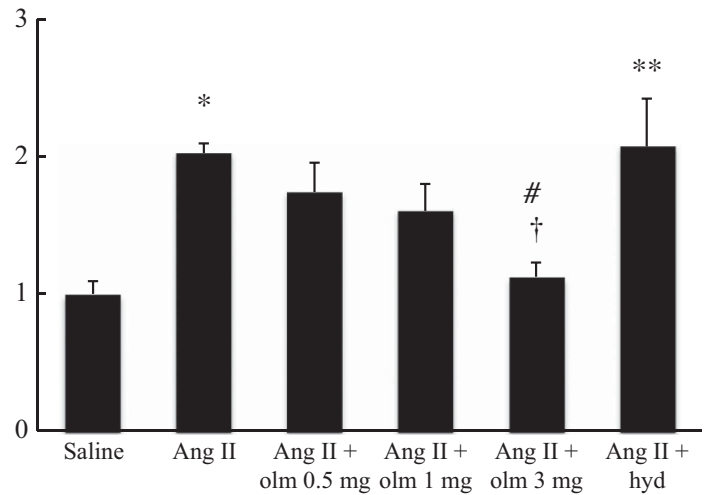

e

Relative expression

MMP-13 / GAPDH

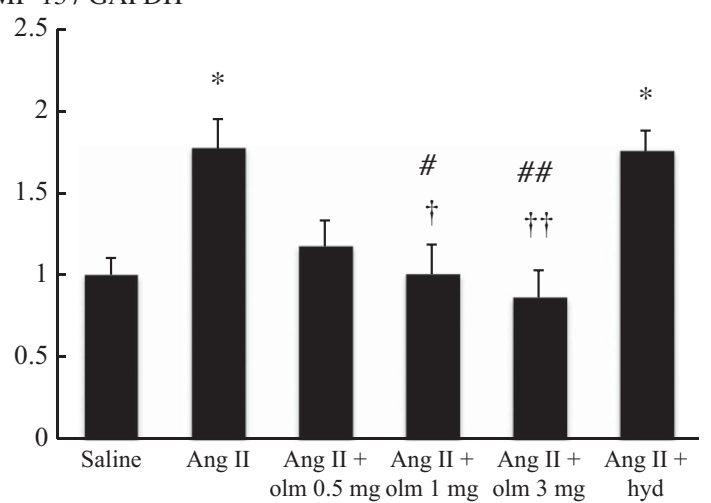

b

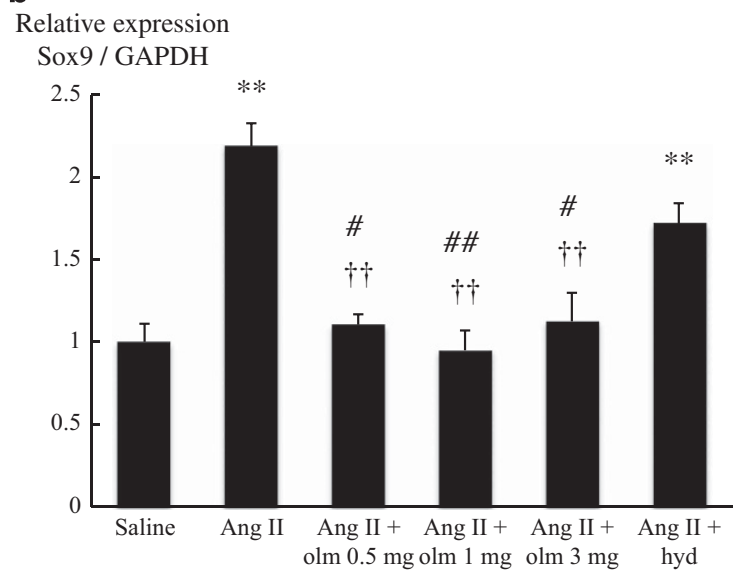

d

Relative expression

type X collagen / GAPDH

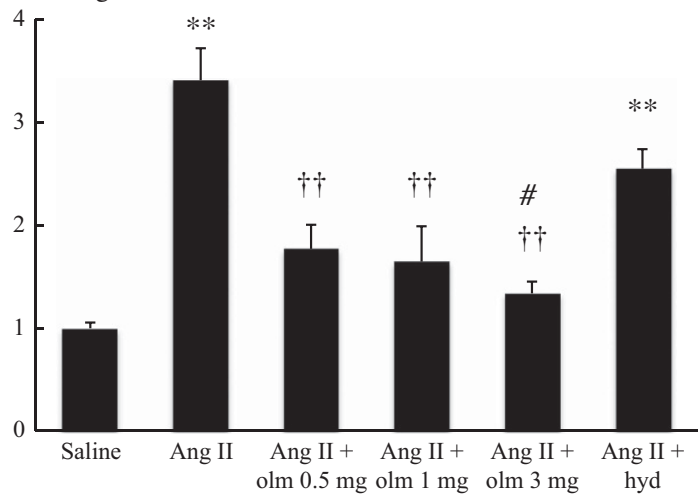

f

Relative expression

Ihh / GAPDH

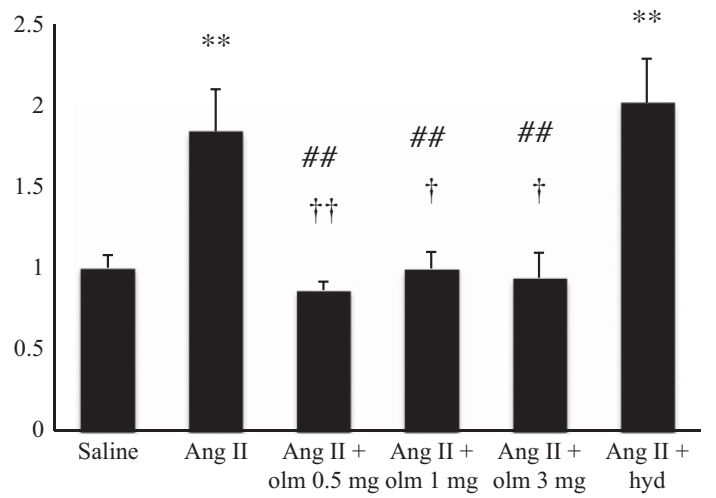

Figure 5 Effect of Ang II infusion on differentiation of chondrocytes. (a) Accumulation of hypertrophic chondrocytes in cartilage after rib fracture at 2 weeks after rib fracture. $N=5$ per group. (b-f) Relative mRNA expression of Sox9 (b), Runx2 (c), type X collagen (d), MMP-13 (e) and Ihh (f) in cartilage at 2 weeks after rib fracture. MP-13, matrix metalloproteinase-13; Ihh, Indian hedgehog. Values are expressed as mean \pm s.e.m. ${ }^{*} P<0.05$ vs. Saline, ${ }^{*} P<0.01$ vs. Saline, ${ }^{\dagger} P<0.05$ vs. Ang II, ${ }^{\dagger} P<0.01$ vs. Ang II, ${ }^{\sharp} P<0.05$ vs. Ang II+Hyd, ${ }^{\#} P<0.01$ vs. Ang $I++H y d . ~ N=5$ per group.

molecular markers and genes related to cell death. The in vivo effect of Ang II on chondrocytes is not yet fully understood.

Thus, the aim of this study was to investigate the in vivo effect of Ang II on chondrocytes. Also, we employed olmesartan as an AT1R blocker and focused on the effect of Ang II via the AT1R pathway. The present study demonstrated that continuous infusion of Ang II resulted in a significant increase in the volume of cartilage, accompanied by accumulation of hypertrophic chondrocytes, suggesting Ang II-induced hypertrophic differentiation of chondrocytes. It could be confirmed by a significant increase in the mRNA expression of Sox 9 and Runx2, which are genes related to chondrocyte differentiation, and type $\mathrm{X}$ collagen, MMP-13 and Ihh, which are hypertrophic 

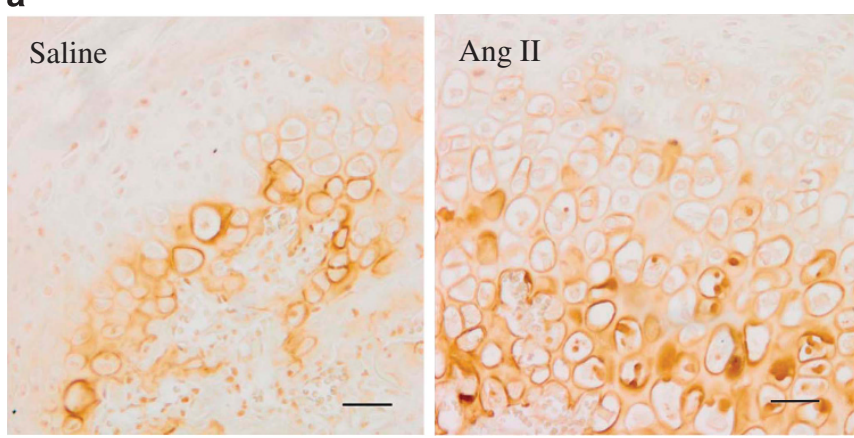
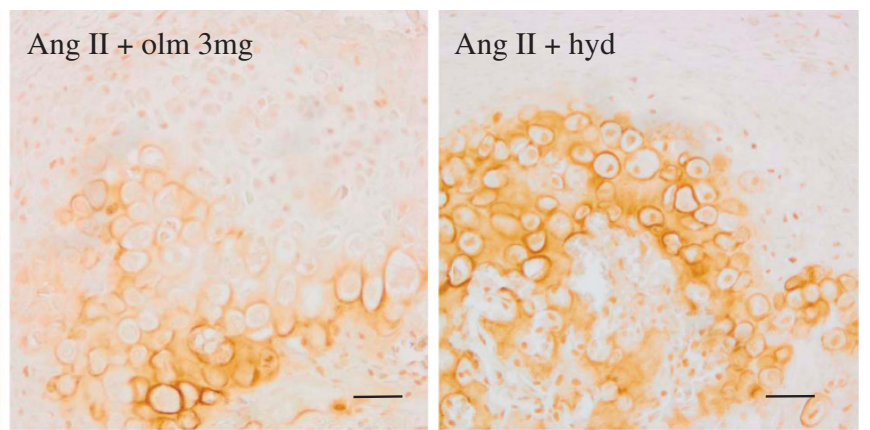

b
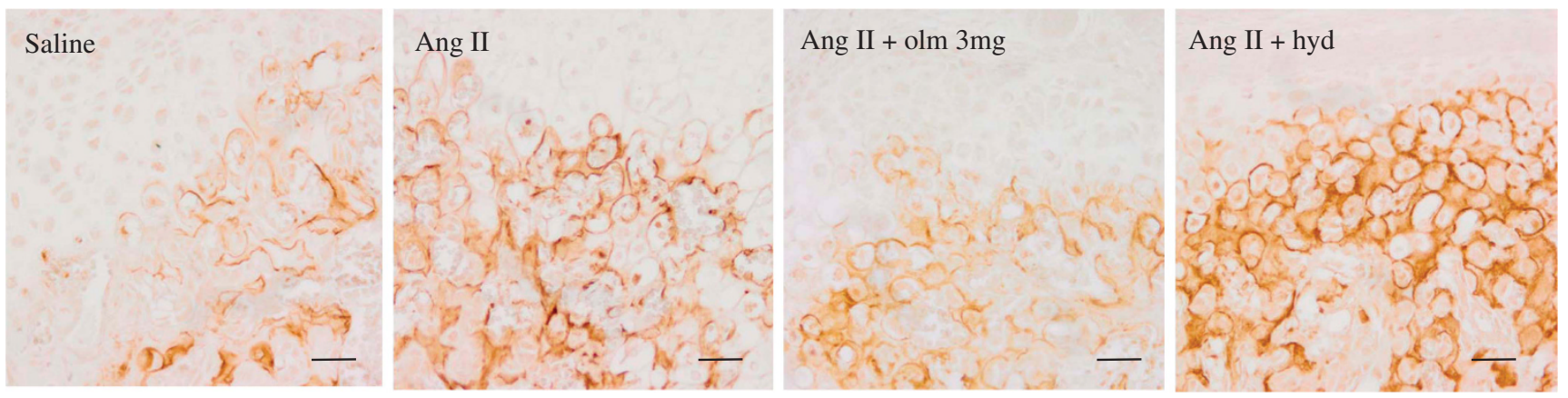

Figure 6 Immunohistochemical staining for type X collagen (a) and MMP-13 (b) in cartilage region at 2 weeks after rib fracture. Magnification is $\times 200$ and scale bar is $50 \mu \mathrm{m}$.

a
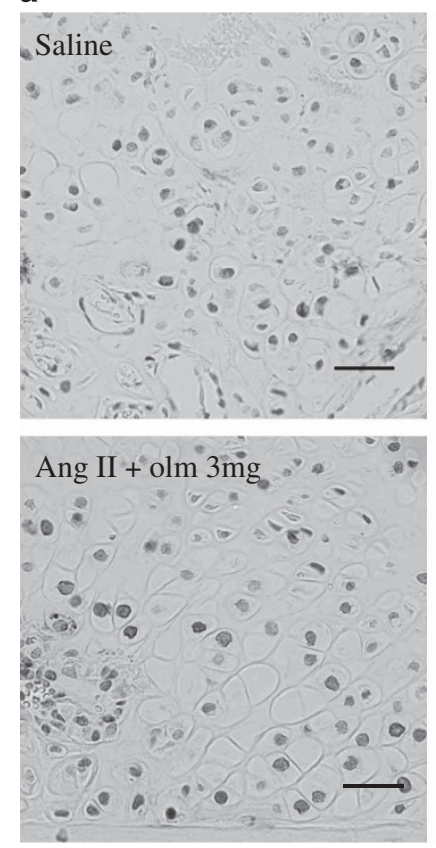
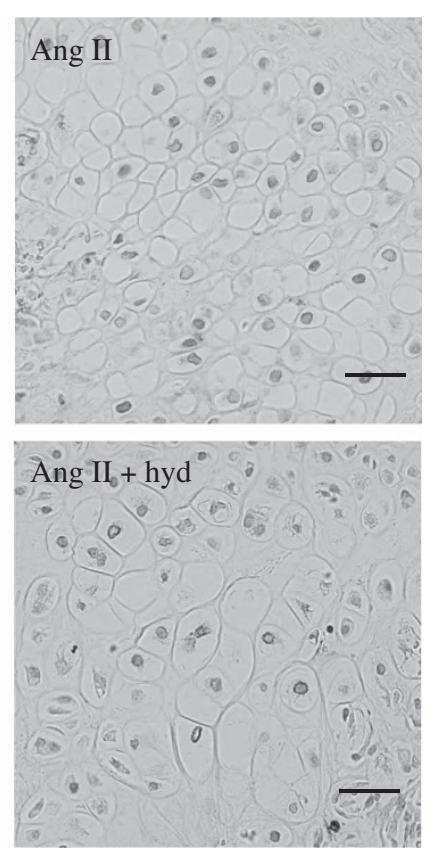

b

Number of

TUNEL positive cells

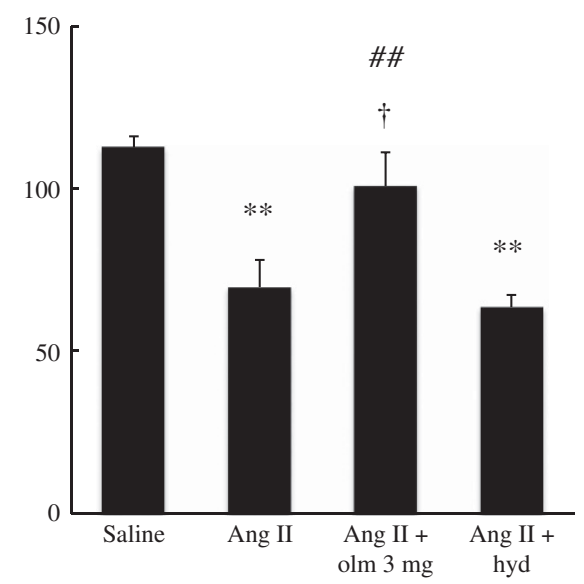

Figure 7 (a) Representative pictures of TUNEL staining in cartilage region at 4 weeks after rib fracture in mice. Magnification is $\times 200$ and scale bar is $50 \mu \mathrm{m}$. (b) Number of TUNEL-positive hypertrophic chondrocytes. Values are expressed as mean \pm s.e.m. ${ }^{* *} P<0.01$ vs. Saline, ${ }^{\dagger} P<0.05$ vs. Ang II, ${ }^{\#} P<0.01$ vs. Ang Il+hyd. $N=5$ per group. A full color version of this figure is available at the Hypertension Research journal online.

chondrocyte-specific molecular markers. Of importance, administration of olmesartan, an ARB, attenuated chondrocyte hypertrophy with upregulation of these genes, whereas hydralazine did not. It indicated that hypertrophic differentiation observed in cartilage formation of an
Ang II-infused fracture mouse was not induced by high BP but by activation of AT1R. Furthermore, Ang II infusion significantly inhibited apoptosis of hypertrophic chondrocytes, which normally occurs for ossification by osteoblasts in the process of fracture healing, 

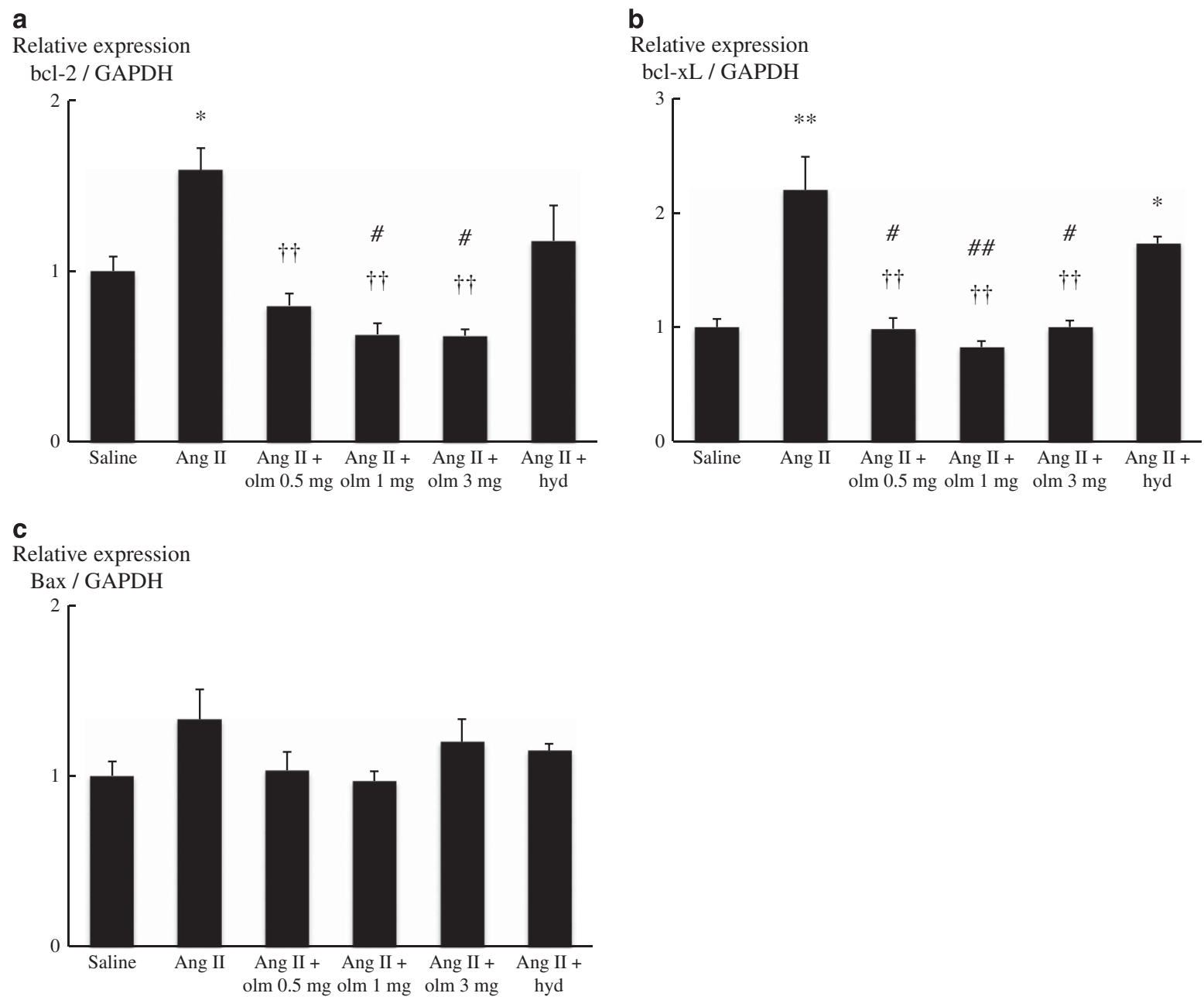

Figure 8 Expression of apoptosis-related genes in cartilage after rib fracture. Relative mRNA expression of bcl-2 (a), bcl-xL (b) and Bax (c) in cartilage at 4 weeks after rib fracture. Values are expressed as mean \pm s.e.m. ${ }^{*} P<0.05$ vs. Saline, ${ }^{* *} P<0.01$ vs. Saline, ${ }^{\dagger \dagger} P<0.01$ vs. Ang II, ${ }^{\# \#} P<0.01$ vs. Ang II +hyd. ${ }^{P}<0.05$ vs. Ang II+hyd.

accompanied with significant induction of mRNA expression of bcl-2 and bcl-xL, anti-apoptotic genes. As a result, infusion of Ang II resulted in maintained accumulation of hypertrophic chondrocytes in cartilage and a delay of endochondral ossification (Figure 1). Our experimental design successfully revealed the in vivo effect of Ang II on chondrocytes. Also, comparison of the effect of olmesartan with that of hydralazine excluded the influence of BP and showed the direct effect of Ang II and AT1R. Here, this study clearly demonstrated the novel findings about in vivo function of Ang II via AT1R activation in hypertrophic differentiation and apoptosis of chondrocytes.

Regarding the present data about effect of Ang II on cell death of chondrocytes, there is a point of uncertainty that should be discussed. The present study demonstrated that Ang II suppressed apoptosis of hypertrophic chondrocytes in the process of fracture healing. However, in general, Ang II is known to induce apoptosis through activation of AT2R in many types of cells. Although it is hard to explain this discrepancy, there is a report ${ }^{42}$ demonstrating that Ang II reduces apoptosis of fibroblast-like synoviocytes from patients with $\mathrm{OA}$ and rheumatoid arthritis via AT1R. Therefore, the effect of Ang II on cell death may depend on cell types. Interestingly, this report demonstrated that Ang II inhibited apoptosis of synoviocytes through the activation of nuclear factor- $\mathrm{\kappa B}$ and the blockage of caspase cascade. ${ }^{42}$ Ang II/AT1R/NF- $\mathrm{KB}$ signaling was also reported in human breast cancer cells. ${ }^{43}$ Moreover, many reports demonstrated preventive effect of NF- $\kappa \mathrm{B}$ on apoptosis of various types of cells. From these findings, Ang II/AT1R/ NF-kB pathway or blockade of caspase cascade via $\mathrm{AT1R}$ are conceivable and speculated molecular mechanisms of Ang II-induced chondrocytes survival.

From previous studies, Runx 2 may be a key molecule explaining the effect of Ang II on chondrocytes shown in the present study. Runx2 is well known as an essential regulator of chondrocyte maturation and hypertrophy, ${ }^{44}$ and overexpression of Runx2 in non-hypertrophic chondrocytes resulted in chondrocyte hypertrophy. ${ }^{45}$ Also, type $\mathrm{X}$ collagen is a direct transcriptional target of Runx2 in cartilage formation. ${ }^{46}$ More interestingly, a study using transgenic mice demonstrated that targeting Runx2 expression in hypertrophic chondrocytes resulted in an elongated hypertrophic zone and delayed skeletal ossification accompanied by upregulation of mRNA expression of marker genes such as type X collagen and Sox $9 .{ }^{25}$ Moreover, this report also showed an increase in bcl-2 expression and a reduction of apoptosis, and concluded that endochondral ossification was impaired by targeting Runx 2 expression in chondrocytes, ${ }^{25}$ consistent with our findings. Although the detail mechanism of interaction between Ang II and Runx2 is still unknown, phosphatidylinositol 3- 
kinase (PI3K)/Akt signaling may link Ang II with Runx2. It was already reported that PI3K/Akt signaling is an important pathway for differentiation of chondrocytes, ${ }^{47}$ and Runx2 induces its differentiation by coupling with PI3K/Akt signaling. ${ }^{48}$ On the other hand, Ang II is also reported to activate PI3K/Akt signaling via AT1R in various cells. ${ }^{43,49}$ Thus, PI3K/Akt signaling is considered to be one of speculated pathways between Ang II and Runx2. Further study to investigate Ang II-induced PI3K/Akt signaling in chondrocytes is needed.

Expression of mRNA of Ang II receptors, both AT1R and AT2R, was observed in articular cartilage obtained from patients and cultured chondrocytes isolated from human articular cartilage. ${ }^{12}$ Although this previous report did not investigate the function of Ang II in chondrocytes, an interesting finding is that stimulation with IL-1 enhanced the expression of both receptors in cultured chondrocytes isolated from articular cartilage of humans with $\mathrm{OA}$, but not in chondrocytes from normal subjects. Moreover, it has been shown that mechanical stress observed in OA activates AT1R. ${ }^{50,51}$ These findings indicate the possibility of implication of a local RAS and Ang II in cartilage denaturation, and our data rationally explain the role of circulating Ang II in the pathogenesis of OA, since circulating Ang II can act on chondrocytes because vascular invasion into articular cartilage induced by expression of vascular endothelial growth factor is one of the major steps in the progression of OA. ${ }^{52,53}$ From our data, it can be suggested that in OA, chondrocyte hypertrophy and inhibition of apoptosis of hypertrophic chondrocytes by Ang II through activation of AT1R continuously increase the expression of type X collagen and MMP-13, followed by cartilage matrix degradation and degeneration. Moreover, we demonstrated that administration of olmesartan, an AT1R blocker, attenuated Ang II-induced hypertrophic differentiation, accompanied by a reduction of expression of type $\mathrm{X}$ collagen and MMP-13. Therefore, treatment with ARBs might have a beneficial and preventive effect on the progression of OA, although further studies are necessary. Considering inhibitory effect of RAS by ACEIs, ACEIs are possible to have the same beneficial effect as ARBs on chondral metabolism of OA.

In the present study inflammation may be an important phenomenon to understand Ang II-induced chondral differentiation. Inflammation is considered to have an important role in differentiation of chondrocytes because (1) inflammation induced by mechanical stress promotes hypertrophic differentiation in the pathogenesis of OA and (2) fracture healing occurs through inflammation. On the other hand, it was already reported that Ang II induces inflammation and that Ang II activates, via AT1R, NF- $\mathrm{B}^{43,54,55}$ which regulates expression of various genes related to inflammation. Furthermore, inflammation by stimulation of IL-1 $\beta$ or tumor necrosis factor- $\alpha$ enhances the expressions of $\mathrm{AT} 1 \mathrm{R},{ }^{14}$ and inflammation by mechanical stress in OA activates AT1R..$^{50,51}$ Considering these findings, contribution of Ang II-induced inflammation to differentiation of chondrocytes is strongly suggested although it is still unclear how inflammation promotes differentiation of chondrocytes.

This study has some limitations that should be investigated in further experiments. First, the role of another Ang II receptor, AT2R, was not evaluated in this study despite the existence of AT2R in cultured chondrocytes. Although there is no report indicating the role of AT2R in vivo, previous in vitro experiments using ATDC5 demonstrated that activation of AT2R enhanced hypertrophic differentiation. ${ }^{13}$ It was demonstrated that stimulation by Ang II and activation of AT1R suppressed hypertrophic differentiation of chondrocytes. This is the opposite result to our present data. Although the reason for this discrepancy cannot be explained, it could be due to different affinity and/or response to Ang II between chondrocytes of the cell line and in vivo chondrocytes. Thus, further study, employing an AT2R blocker (PD123319), is expected to elucidate the functions of AT2R, which may have an opposite effect on chondrocytes in vivo. Second, the function of metabolic products of Ang II such as Ang 1-7 and Ang 3-8, which could be considered to reverse the effect of Ang II, was not evaluated. Although this study successfully showed the effect of Ang II on chondrocytes, further study focused on the metabolic products of Ang II is needed to elucidate the precise mechanism of RAS in cartilage. Finally, the influence of sex hormones, especially the estrous cycle, should be considered in this study because female mice were used in our experiments. Estrogen receptors, both ER $\alpha$ and ER $\beta$, are reported to be expressed in cultured chondrocytes ${ }^{56}$ and growth plate cartilage from various species. ${ }^{57,58}$ Moreover, it was reported that estrogen promotes chondrocyte proliferation and differentiation in the normal regulation of growth plate and longitudinal bone growth. ${ }^{59-61}$ Also, it was suggested that estrogen decreased apoptosis of chondrocytes. ${ }^{59}$ Therefore, the effect of Ang II on hypertrophic differentiation and apoptosis of chondrocytes demonstrated by our experimental design may include the influence of estrogen. However, some reports have demonstrated an opposite effect or no effect of estrogen on chondrocyte metabolism, ${ }^{62,63}$ and our preliminary data demonstrated no significant difference in cartilage volume at 2 weeks after a rib fracture between male and female mice both under and without continuous infusion of Ang II (data not shown), suggesting that the influence of estrogen on our results is limited.

In conclusion, the present study demonstrated that Ang II promoted hypertrophic differentiation of chondrocytes and reduced apoptosis of hypertrophic chondrocytes via AT1R activation. Also, Ang II increased the expression of genes related to hypertrophic differentiation and cartilage matrix regeneration. Olmesartan, an AT1R blocker, but not hydralazine, attenuated the hypertrophic differentiation of chondrocytes induced by Ang II, suggesting that the effect of Ang II on chondrocytes was independent of BP. The findings of this paper may help to elucidate the role of Ang II and AT1R in the progression of degenerative cartilage disease such as OA, and suggest that OA is expectedly benefited by inhibition of RAS by ARBs or ACEIs. In addition to the role of Ang II and Ang II receptors in bone remodeling as previously reported, the present data might provide a new concept for comprehensive treatment of the locomotive syndrome based on osteoporosis and OA, centering on RAS.

\section{CONFLICT OF INTEREST}

The authors declare no conflict of interest.

\section{ACKNOWLEDGEMENTS}

We wish to thank Touru Yutani, Hiroshi Kawanami and Miyuki Mori for their excellent technical assistance. Olmesartan was kindly provided by Daiichi Sankyo. This study was supported by the Japan Society for the Promotion of Science (JSPS; grant number: 24590906) (http://www.jsps.go.jp/english/index. html). JSPS and Daiichi Sankyo had no participation in the study design, data collection and analysis, decision to publish, or preparation of the manuscript.

1 Peach MJ. Renin-angiotensin system: biochemistry and mechanisms of action. Physiol Rev 1977; 57: 313-370.

2 Paul M, Poyan Mehr A, Kreutz R. Physiology of local renin-angiotensin systems. Physiol Rev 2006; 86: 747-803.

3 Balakumar P, Jagadeesh G. A century old renin-angiotensin system still grows with endless possibilities: AT1 receptor signaling cascades in cardiovascular physiopathology. Cell Signal 2014; 26: 2147-2160. 
4 Speth RC, Vento PJ, Carrera EJ, Gonzalez-Reily L, Linares A, Santos K, Swindle JD, Daniels $D$. Acute repeated intracerebroventricular injections of angiotensin II reduce agonist and antagonist radioligand binding in the paraventricular nucleus of the hypothalamus and median preoptic nucleus in the rat brain. Brain Res 2014; 2: $132-140$

5 Mezzano SA, Ruiz-Ortega M, Egido J. Angiotensin II and renal fibrosis. Hypertension 2001; 38: 635-638.

6 Yoshida T, Huq TS, Delafontaine P. Angiotensin type 2 receptor signaling in satellite cells potentiates skeletal muscle regeneration. J Biol Chem 2014; 289: 26239-26248

7 Maeda A, Tamura K, Wakui H, Ohsawa M, Azushima K, Uneda K, Kanaoka T, Kobayashi R, Ohki K, Matsuda M, Tsurumi-Ikeya Y, Yamashita A, Tokita Y, Umemura S. Effects of the angiotensin receptor blocker olmesartan on adipocyte hypertrophy and function in mice with metabolic disorders. Biomed Res Int 2014; 2014: 946492.

8 Liu SS, Wang HY, Tang JM, Zhou XM. Hypoxia-induced collagen synthesis of human lung fibroblasts by activating the angiotensin system. Int J Mol Sci 2013; 14: 24029-24045

9 Mancini GB, Etminan M, Zhang B, Levesque LE, FitzGerald JM, Brophy JM. Reduction of morbidity and mortality by statins, angiotensin-converting enzyme inhibitors, and angiotensin receptor blockers in patients with chronic obstructive pulmonary disease. $J$ Am Coll Cardiol 2006; 47: 2554-2560.

10 Kehoe PG, Passmore PA. The renin-angiotensin system and antihypertensive drugs in Alzheimer's disease: current standing of the angiotensin hypothesis? J Alzheimers Dis 2012; 30: S251-S268.

11 Shimizu H, Nakagami H, Osako MK, Hanayama R, Kunugiza Y, Kizawa T, Tomita T, Yoshikawa H, Ogihara T, Morishita R. Angiotensin II accelerates osteoporosis by activating osteoclasts. FASEB J 2008; 22: 2465-2475.

12 Kawakami Y, Matsuo K, Murata M, Yudoh K, Nakamura H, Shimizu H, Beppu M, Inaba Y, Saito T, Kato T, Masuko K. Expression of angiotensin II receptor-1 in human articular chondrocytes. Arthritis 2012; 2012: 648537.

13 Tsukamoto 1, Inoue S, Teramura T, Takehara T, Ohtani K, Akagi M. Activating types 1 and 2 angiotensin II receptors modulate the hypertrophic differentiation of chondrocytes. FEBS Open Bio 2013; 3: 279-284.

14 Tsukamoto I, Akagi M, Inoue S, Yamagishi K, Mori S, Asada S. Expressions of local renin-angiotensin system components in chondrocytes. Eur J Histochem 2014; 58 2387.

15 Garcia P, Schwenzer S, Slotta JE, Scheuer C, Tami AE, Holstein JH, Histing T, Burkhardt M, Pohlemann T, Menger MD. Inhibition of angiotensin-converting enzyme stimulates fracture healing and periosteal callus formation-role of a local reninangiotensin system. Br J Pharmacol 2010; 159: 1672-1680.

16 Zhao X, Wu ZX, Zhang Y, Gao MX, Yan YB, Cao PC, Zang Y, Lei W. Locally administrated perindopril improves healing in an ovariectomized rat tibial osteotomy model. PLOS ONE 2010; 7: e33228.

17 Maes C, Kobayashi T, Selig MK, Torrekens S, Roth SI, Mackem S, Carmeliet G, Kronenberg HM. Osteoblast precursors, but not mature osteoblasts, move into developing and fractured bones along with invading blood vessels. Dev Cell 2010; 19 329-344.

18 Kawahata H, Kikkawa T, Higashibata Y, Sakuma T, Huening M, Sato M, Sugimoto M Kuriyama K, Terai K, Kitamura Y, Nomura S. Enhanced expression of Runx2/ PEBP2alphaA/CBFA1/AML3 during fracture healing. J Orthop Sci 2003; 8: $102-108$

19 Yutani T, Kawahata H, Sotobayashi D, Kawanami H, Aoki M. Anti-inflammatory effect of electro-acupuncture via reduction in colonic peristalsis in a mouse model of inflammatory bowel disease. Immunol Endocr Metab Agents Med Chem 2013; 13 122-131.

20 Huang Y, Zhang X, Du K, Yang F, Shi Y, Huang J, Tang T, Chen D, Dai K. Inhibition of beta-catenin signaling in chondrocytes induces delayed fracture healing in mice. J Orthop Res 2012; 30: 304-310.

$21 \mathrm{Fu} \mathrm{H}$, Doll B, McNelis T, Hollinger JO. Osteoblast differentiation in vitro and in vivo promoted by Osterix. J Biomed Mater Res 2007; 83: 770-778.

22 Takarada T, Kodama A, Hotta S, Mieda M, Shimba S, Hinoi E, Yoneda Y. Clock genes influence gene expression in growth plate and endochondral ossification in mice. J Biol Chem 2012; 287: 36081-36095.

23 Rundle $\mathrm{CH}$, Wang $\mathrm{X}$, Sheng MH, Wergedal JE, Lau KH, Mohan S. Bax deficiency in mice increases cartilage production during fracture repair through a mechanism involving increased chondrocyte proliferation without changes in apoptosis. Bone 2008; 43: 880-888.

24 Cuesta-Domínguez Á, Ortega M, Ormazábal C, Santos-Roncero M, Galán-Díez M, Steegmann JL, Figuera Á, Arranz E, Vizmanos JL, Bueren JA, Río P, Fernández-Ruiz E. Transforming and tumorigenic activity of JAK2 by fusion to BCR: molecular mechanisms of action of a novel BCR-JAK2 tyrosine-kinase. PLOS ONE 2012; 7: e32451.

25 Ding M, Lu Y, Abbassi S, Li F, Li X, Song Y, Geoffroy V, Im HJ, Zheng Q. Targeting Runx2 expression in hypertrophic chondrocytes impairs endochondral ossification during early skeletal development. J Cell Physiol 2012; 227: 3446-3456.

26 Platten M, Youssef S, Hur EM, Ho PP, Han MH, Lanz TV, Phillips LK, Goldstein MJ, Bhat R, Raine CS, Sobel RA, Steinman L. Blocking angiotensin-converting enzyme induces potent regulatory T cells and modulates TH1- and TH17-mediated autoimmunity. Proc Natl Acad Sci USA 2009; 106: 14948-14953.

27 Chauhan VP, Martin JD, Liu H, Lacorre DA, Jain SR, Kozin SV, Stylianopoulos T, Mousa AS, Han X, Adstamongkonkul P, Popović Z, Huang P, Bawendi MG, Boucher Y, Jain RK. Angiotensin inhibition enhances drug delivery and potentiates chemotherapy by decompressing tumour blood vessels. Nat Commun 2013; 4: 2516.
28 Pérez-Castrillón JL, Silva J, Justo I, Sanz A, Martín-Luquero M, Igea R, Escudero P, Pueyo C, Díaz C, Hernández G, Dueñas A. Effect of quinapril, quinapril-hydrochlorothiazide, and enalapril on the bone mass of hypertensive subjects: relationship with angiotensin converting enzyme polymorphisms. Am J Hypertens 2003; 16: 453-459.

29 Lynn H, Kwok T, Wong SY, Woo J, Leung PC. Angiotensin converting enzyme inhibitor use is associated with higher bone mineral density in elderly Chinese. Bone 2006; 38: 584-588.

30 Aoki M, Kawahata H, Sotobayashi D, Yu H, Moriguchi A, Nakagami H, Ogihara T, Morishita R. Effect of angiotensin II receptor blocker, olmesartan, on turnover of bone metabolism in bedridden elderly hypertensive women with disuse syndrome. Geriatr Gerontol Int 2014; 3: 12406.

31 Hatton R, Stimpel M, Chambers TJ. Angiotensin II is generated from angiotensin I by bone cells and stimulates osteoclastic bone resorption in vitro. J Endocrinol 1997; 152: 5-10.

32 Hiruma Y, Inoue A, Hirose S, Hagiwara H. Angiotensin II stimulates the proliferation of osteoblast-rich populations of cells from rat calvariae. Biochem Biophys Res Commun 1997; 230: 176-178.

33 Shimizu H, Nakagami H, Osako MK, Nakagami F, Kunugiza Y, Tomita T, Yoshikawa H, Rakugi H, Ogihara T, Morishita R. Prevention of osteoporosis by angiotensin-converting enzyme inhibitor in spontaneous hypertensive rats. Hypertens Res 2009; 32: 786-790.

34 Izu Y, Mizoguchi F, Kawamata A, Hayata T, Nakamoto T, Nakashima K, Inagami T, Ezura Y, Noda M. Angiotensin II type 2 receptor blockade increases bone mass. J Biol Chem 2009; 284: 4857-4864.

35 Asaba Y, Ito M, Fumoto T, Watanabe K, Fukuhara R, Takeshita S, Nimura Y, Ishida J, Fukamizu A, Ikeda K. Activation of renin-angiotensin system induces osteoporosis independently of hypertension. J Bone Miner Res 2009; 24: 241-250.

36 Schurman SJ, Bergstrom WH, Shoemaker LR, Welch TR. Angiotensin II reduces calcium uptake into bone. Pediatr Nephrol 2004; 19: 33-35.

37 Kaneko K, Ito M, Fumoto T, Fukuhara R, Ishida J, Fukamizu A, Ikeda K. Physiologica function of the angiotensin ATla receptor in bone remodeling. J Bone Miner Res 2011; 26: 2959-2966

38 Wang Y, Peng R, Ma R. Epidemiological investigation of osteoarthritis in middle-aged Mongolian and senior residents of the Inner Mongolia autonomous region. Iran Red Crescent Med J 2013; 15: e8303.

39 Rahman MM, Kopec JA, Cibere J, Goldsmith $\mathrm{CH}$, Anis AH. The relationship between osteoarthritis and cardiovascular disease in a population health survey: a crosssectional study. BMJ Open 2013; 3: e002624.

40 Sagawa K, Nagatani K, Komagata Y, Yamamoto K. Angiotensin receptor blockers suppress antigen-specific $T$ cell responses and ameliorate collagen-induced arthritis in mice. Arthritis Rheum 2005. 52. 1920-1928.

41 Price A, Lockhart JC, Ferrell WR, Gsell W, McLean S, Sturrock RD. Angiotensin II type 1 receptor as a novel therapeutic target in rheumatoid arthritis: in vivo analyses in rodent models of arthritis and ex vivo analyses in human inflammatory synovitis. Arthritis Rheum 2007; 56: 441-447.

42 Pattacini L, Casali B, Boiardi L, Pipitone N, Albertazzi L, Salvarani C. Angiotensin II protects fibroblast-like synoviocytes from apoptosis via the AT1-NF-kappaB pathway. Rheumatology 2007; 46: 1252-1257.

43 Zhao Y, Wang H, Li X, Cao M, Lu H, Meng Q, Pang H, Li H, Nadolny C, Dong X, Cai L. Ang II-AT1R increases cell migration through PI3K/AKT and NF-KB pathways in breast cancer. J Cell Physiol 2014; 229: 1855-1862.

44 Karsenty G. Minireview: transcriptional control of osteoblast differentiation. Endocrinol ogy 2001; 142: 2731-2733.

45 Takeda S, Bonnamy JP, Owen MJ, Ducy P, Karsenty G. Continuous expression of Cbfa1 in nonhypertrophic chondrocytes uncovers its ability to induce hypertrophic chondrocyte differentiation and partially rescues Cbfal-deficient mice. Genes Dev 2001; 15: 467-481.

46 Zheng Q, Zhou G, Morello R, Chen Y, Garcia-Rojas X, Lee B. Type X collagen gene regulation by Runx2 contributes directly to its hypertrophic chondrocyte-specific expression in vivo. J Cell Biol 2003; 162: 833-842.

47 Kita K, Kimura T, Nakamura N, Yoshikawa H, Nakano T. PI3K/Akt signaling as a key regulatory pathway for chondrocyte terminal differentiation. Genes Cells 2008; 13 839-850.

48 Fujita T, Azuma Y, Fukuyama R, Hattori Y, Yoshida C, Koida M, Ogita K, Komori T. Runx2 induces osteoblast and chondrocyte differentiation and enhances their migration by coupling with PI3K-Akt signaling. J Cell Biol 2004; 166: 85-95.

49 Zheng X, Wu Y, Zhu L, Chen Q, Zhou Y, Yan H, Chen T, Xiao Q, Zhu J, Zhang L. Angiotensin II promotes differentiation of mouse embryonic stem cells to smooth muscle cells through PI3-kinase signaling pathway and NF-kB. Differentiation 2013, 85: 41-54.

50 Zou Y, Akazawa H, Qin Y, Sano M, Takano H, Minamino T, Makita N, Iwanaga K, Zhu W, Kudoh S, Toko H, Tamura K, Kihara M, Nagai T, Fukamizu A, Umemura S, liri T, Fujita T, Komuro I. Mechanical stress activates angiotensin II type 1 receptor without the involvement of angiotensin II. Nature Cell Biology 2004; 6: 499-506.

51 Yasuda N, Akazawa H, Qin Y, Zou Y, Komuro I. A novel mechanism of mechanical stress-induced angiotensin II type 1-receptor activation without the involvement of angiotensin II. Naunyn-Schmiedebergs Arch Pharmacol 2008; 377: 393-399.

52 Fransès RE, McWilliams DF, Mapp PI, Walsh DA. Osteochondral angiogenesis and increased protease inhibitor expression in OA. Osteoarthritis Cartilage 2010; 18 563-571.

53 Jansen $\mathrm{H}$, Meffert RH, Birkenfeld F, Petersen W, Pufe T. Detection of vascular endothelial growth factor (VEGF) in moderate osteoarthritis in a rabbit model. Ann Anat 2010; 194: 452-456. 
54 Wang AW, Song L, Miao J, Wang HX, Tian C, Jiang X, Han QY, Yu L, Liu Y, Du J, Xia YL, $\mathrm{Li} \mathrm{HH}$. Baicalein attenuates angiotensin II-induced cardiac remodeling via inhibition of AKT/mTOR, ERK $1 / 2, N F-\kappa B$, and calcineurin signaling pathways in mice. Am J Hypertens 2014; 31: 194

55 Alique M, Sánchez-López E, Rayego-Mateos S, Egido J, Ortiz A, Ruiz-Ortega M. Angiotensin II, via angiotensin receptor type 1 /nuclear factor-kB activation, causes a synergistic effect on interleukin-1- $\beta$-induced inflammatory responses in cultured mesangial cells. J Renin Angiotensin Aldosterone Syst (e-pub ahead of print 29 October 2014).

56 Wang SJ, Li XF, Jiang LS, Dai LY. Estrogen stimulates leptin receptor expression in ATDC5 cells via the estrogen receptor and extracellular signal-regulated kinase pathways. J Endocrinol 2012; 213: 163-172.

57 Yao X, Chen H, Ohtake N, Shoumura S. Morphological alterations in the growth plate cartilage of ovariectomized mice. Med Mol Morphol 2006; 39: 193-197.

58 Nilsson O, Abad V, Chrysis D, Ritzen EM, Savendahl L, Baron J. Estrogen receptor-alpha and -beta are expressed throughout postnatal development in the rat and rabbit growth plate. J Endocrinol 2002; 173: 407-414.
59 Chagin AS, Chrysis D, Takigawa M, Ritzen EM, Sävendahl L. Locally produced estrogen promotes fetal rat metatarsal bone growth; an effect mediated through increased chondrocyte proliferation and decreased apoptosis. J Endocrinol 2006; 188: 193-203.

60 Vidal O, Lindberg MK, Hollberg K, Baylink DJ, Andersson G, Lubahn DB, Mohan S, Gustafsson JA, Ohlsson C. Estrogen receptor specificity in the regulation of skeletal growth and maturation in male mice. Proc Natl Acad Sci USA 2000; 97 : 5474-5479.

61 Emons J, Chagin AS, Malmlöf T, Lekman M, Tivesten A, Ohlsson C, Wit JM, Karperien $M$, Sävendahl L. Expression of vascular endothelial growth factor in the growth plate is stimulated by estradiol and increases during pubertal development. J Endocrinol 2010; 205: 61-68.

62 Rodd C, Jourdain N, Alini M. Action of estradiol on epiphyseal growth plate chondrocytes. Calcif Tissue Int 2004; 75: 214-224.

63 Turner RT, Evans GL, Wakley GK. Reduced chondroclast differentiation results in increased cancellous bone volume in estrogen-treated growing rats. Endocrinology 1994; 134: 461-466. 